\title{
Risk factors for an early dialysis start in patients with diabetic nephropathy end-stage renal disease
}

This article was published in the following Dove Press journal:

Therapeutics and Clinical Risk Management

30 January 2014

Number of times this article has been viewed

\author{
Tomohiro Mizuno ${ }^{1,2, *}$ \\ Takahiro Hayashi, ${ }^{3, *}$ \\ Rina Kato' \\ Ayaka Noguchi' \\ Hiroki Hayashi ${ }^{2}$ \\ Yukio Yuzawa ${ }^{2}$ \\ Shigeki Yamada ${ }^{3}$ \\ Tadashi Nagamatsu' \\ 'Department of Analytical \\ Pharmacology, Meijo University \\ Faculty of Pharmacy, Nagoya; \\ ${ }^{2}$ Department of Nephrology, \\ ${ }^{3}$ Department of Clinical Pharmacy, \\ School of Medicine, Fujita Health \\ University, Toyoake, Japan \\ *These authors contributed equally to \\ this work
}

Correspondence: Tadashi Nagamatsu Department of Analytical Pharmacology, Meijo University Faculty of Pharmacy,

I50 Yagotoyama, Tempaku,

Nagoya 468-8503, Japan

Email nagamats@meijo-u.ac.jp
Background: Patients with end-stage renal disease (ESRD) have symptoms related to severe anemia, edema, and heart failure. Although dialysis improves ESRD syndromes, the optimum timing for initiation of dialysis is unclear. Recent observational studies have suggested that early commencement of dialysis can be harmful. Given that early dialysis may increase the risk of death, avoiding an early start to dialysis is recommended. Patients with diabetic nephropathy (DN) may have risk factors for early dialysis. However, the risk factors for early dialysis are unclear in ESRD patients with DN. The aim of this study was to elucidate the risk factors for early initiation of dialysis in patients with DN and ESRD.

Methods: From April 2009 to December 2012, we identified Japanese DN patients with an estimated glomerular filtration rate of less than $15 \mathrm{~mL} /$ minute $/ 1.73 \mathrm{~m}^{2}$. The patients were divided into late or early dialysis groups based on the timing of start of dialysis.

Results: We evaluated 52 patients who commenced dialysis during the observation period, including 33 in the late dialysis group and 19 in the early dialysis group. There was a significant association between early dialysis and age $\geq 65$ years (odds ratio 4.59 ). The incidence of pneumonia before starting dialysis was significantly higher in elderly patients than in nonelderly patients.

Conclusion: Our findings suggest that elderly patients with DN and ESRD have an increased risk of early initiation of dialysis, and occurrence of pneumonia is also associated with early dialysis. To avoid early commencement of dialysis, booster pneumococcal vaccination could be useful in elderly DN patients with ESRD.

Keywords: early dialysis, diabetes mellitus, nephropathy, elderly patients, estimated glomerular filtration rate

\section{Introduction}

There are over 300,000 patients on dialysis in Japan. ${ }^{1}$ To reduce the need for initiation of dialysis, management of patients with end-stage renal disease (ESRD) is important. Patients with ESRD have severe anemia, edema, and heart failure. ${ }^{2}$ Symptoms of ESRD influence daily activities, and thus are important for deciding when to start dialysis. Although dialysis improves the symptoms of ESRD, the optimum timing of its initiation is unclear.

A number of studies have been performed regarding the timing of commencement of dialysis, and early or late initiation of dialysis has been guided by renal function. Older studies suggest that early initiation of dialysis improves survival and decreases complications. ${ }^{3-5}$ However, more recent observational data have suggested that an early start to dialysis is harmful..$^{6-10}$ The Initiating Dialysis Early and Late study demonstrated 
that an early start to dialysis was not associated with improvement of survival or clinical outcomes, ${ }^{11}$ with the difference between the early and late dialysis groups being 5.6 months. ${ }^{11}$ Pan et al reported that an early start to dialysis was associated with an increased risk of mortality, ${ }^{12}$ suggesting that early dialysis should be avoided.

Recently, the number of patients with diabetes mellitus has been increasing rapidly, and diabetic nephropathy (DN) has become the primary reason for starting dialysis. ${ }^{13}$ Mortality in patients with DN is higher after commencement of dialysis, ${ }^{12}$ but the risk factors for early initiation of dialysis are unclear in patients with DN and ESRD. Accordingly, the aim of this study was to elucidate the risk factors for early dialysis in DN patients with ESRD.

\section{Materials and methods}

This retrospective cohort study was approved by the ethics board of Fujita Health University Hospital, and all data were extracted from patient medical records. From April 2009 to December 2012, we identified Japanese DN patients aged $\geq 18$ years with ESRD and an estimated glomerular filtration rate (eGFR) under $15 \mathrm{~mL} /$ minute $/ 1.73 \mathrm{~m}^{2} .{ }^{14}$ The eGFR values were single measurements. DN was identified from the diagnosis in the medical record. The primary endpoint of the study was early initiation of dialysis.

Renal function was evaluated by calculating the eGFR via the modified Modification of Diet in Renal Disease equation. ${ }^{15}$ An early start to dialysis was defined according to our criteria which were based on the Initiating Dialysis Early and Late study ${ }^{11}$ and European Renal Association. ${ }^{16}$ Our criterion for dividing the patients into late and early dialysis groups was eGFR $\leq 7 \mathrm{~mL} /$ minute $/ 1.73 \mathrm{~m}^{2}$ when dialysis was initiated (late dialysis) and eGFR $>7 \mathrm{~mL} / \mathrm{minute} / 1.73 \mathrm{~m}^{2}$ when dialysis was initiated (early dialysis).

The baseline characteristics of the subjects are shown in Table 1 . Elderly patients were defined as those aged $\geq 65$ years. Hypertension was defined as treatment with antihypertensive drugs, systolic blood pressure $\geq 140 \mathrm{mmHg}$, or diastolic blood pressure $\geq 90 \mathrm{mmHg}$. Average values over many months were used to diagnose hypertension. Hyperlipidemia was defined as treatment with lipid-lowering therapy. Heart failure, anemia, and malignancy were identified from the medical records. Pneumonia was also defined from diagnoses in the medical records during the observation period between initiation of dialysis and the start of this study.

Mean values and nominal data were compared using the Student's $t$-test or Fisher's exact test, respectively.
Table I Baseline characteristics of the late and early dialysis groups

\begin{tabular}{|c|c|c|c|}
\hline Characteristic & $\begin{array}{l}\text { Late dialysis } \\
\text { group } \\
(n=33)\end{array}$ & $\begin{array}{l}\text { Early dialysis } \\
\text { group } \\
(n=19)\end{array}$ & $P$-value \\
\hline Male (\%) & 24 (73\%) & $18(95 \%)$ & $0.052^{b}$ \\
\hline Age (years) & $61.2(30-85)$ & $68.7(58-80)$ & $0.004^{a}$ \\
\hline Elderly patients (\%) & $13(39 \%)$ & $15(79 \%)$ & $0.006^{\mathrm{b}}$ \\
\hline $\begin{array}{l}\text { Serum creatinine } \\
(\mathrm{mg} / \mathrm{dL})\end{array}$ & $3.8(2.5-7.0)$ & $3.7(2.5-5.5)$ & $0.488^{a}$ \\
\hline $\begin{array}{l}\text { eGFR } \\
\left(\mathrm{mL} / \text { minute } / \mathrm{l} .73 \mathrm{~m}^{2}\right)\end{array}$ & | $3.0(7.5-\mid 4.9)$ & $13.9(8.9-14.9)$ & $0.077^{a}$ \\
\hline Potassium (mEq/L) & $4.6(3.1-6.1)$ & $4.5(3.3-5.6)$ & $0.577^{\mathrm{a}}$ \\
\hline Hemoglobin $(\mathrm{g} / \mathrm{dL})$ & $9.9(6.9-12.4)$ & $9.8(7.7-12.4)$ & $0.814^{a}$ \\
\hline $\begin{array}{l}\text { Blood urea } \\
\text { nitrogen }(\mathrm{mg} / \mathrm{dL})\end{array}$ & $48.3(29.4-85.9)$ & $47.2(26.0-140.2)$ & $0.836^{a}$ \\
\hline Uric acid $(\mathrm{mg} / \mathrm{dL})$ & $7.0(3.0-10.5)$ & $7.4(4.9-13.8)$ & $0.647^{\mathrm{a}}$ \\
\hline Albumin $(\mathrm{g} / \mathrm{dL})$ & $3.2(2.0-4.2)$ & $3.2(2.5-4.0)$ & $0.547^{a}$ \\
\hline Hypertension (\%) & $32(97 \%)$ & $19(100 \%)$ & $0.778^{b}$ \\
\hline Heart failure (\%) & $12(36 \%)$ & $10(53 \%)$ & $0.253^{b}$ \\
\hline Hyperlipidemia (\%) & 26 (79\%) & $12(63 \%)$ & $0.22 \mathrm{I}^{\mathrm{b}}$ \\
\hline Anemia (\%) & 30 (91\%) & $18(95 \%)$ & $0.618^{b}$ \\
\hline Malignancy (\%) & $5(15 \%)$ & $5(26 \%)$ & $0.325^{b}$ \\
\hline
\end{tabular}

Notes: Data are presented as the mean (range) or number of subjects (percentage). $P$-values were calculated using the Student's $t$-test ${ }^{a}$ or Fisher's exact test. ${ }^{b}$ Abbreviation: eGFR, estimated glomerular filtration rate.

Multivariate logistic regression analysis was used to identify predictors of early dialysis, with selection of parameters that showed statistical significance or were clinically important, ie, male sex, age $\geq 65$ years, heart failure, and anemia. The final multivariable model was applied with variables entered one at a time (forward selection). The predictive ability of the model was quantified using Hosmer-Lemeshow goodnessof-fit test. In these tests, a two-sided $P$-value of $<0.05$ was considered to be statistically significant. IBM SPSS Statistics for Windows version 20.0 software (IBM Corporation, Armonk, NY, USA) was used for the statistical analysis.

\section{Results}

We evaluated 52 patients who started dialysis during the observation period and classified them into late dialysis $(n=33)$ and early dialysis $(n=19)$ groups. The baseline characteristics of the two groups are listed in the Materials and methods section. Mean age and percentage of elderly patients (aged $\geq 65$ years) were significantly higher in the early dialysis group than in the late dialysis group. Baseline renal function was similar in the two groups. The percentage of male patients did not differ significantly between the two groups, but was higher in the early dialysis group. Morbidity rates for hypertension, heart failure, hyperlipidemia, anemia, and malignancy were not significantly different between the groups. 
There was a significant association between early dialysis and patient age (odds ratio $4.59, P=0.030$ ), as well as a weak association with male sex (odds ratio 8.45, $P=0.080$, Table 2). The multiple logistic regression model was well calibrated between the deciles of observed and expected risk in the late and early dialysis groups (Hosmer-Lemeshow test, $P=0.736$ ). The incidence of pneumonia before starting dialysis was significantly higher in elderly patients than in nonelderly patients (see Figure 1).

\section{Discussion}

In the present study, we found that elderly patients with DN and ESRD had a higher risk of early initiation of dialysis. Male patients also had a higher risk of early dialysis, but their increased risk was not significant. Moreover, elderly DN patients with ESRD had a higher risk of developing pneumonia.

Lassalle et al reported that advancing age, male sex, diabetes mellitus, cardiovascular disease, low body mass index, and hypoalbuminemia were risk factors for initiation of dialysis at a higher eGFR. ${ }^{8}$ However, the reasons for early commencement of dialysis in elderly patients with DN have been unclear. Although our criteria for defining early and late dialysis were different from those used by Lassalle et al, our results are to some extent consistent with theirs. Interestingly, the incidence of pneumonia was higher in elderly patients with DN than in their nonelderly counterparts. Given that severe infections induce hypercatabolism in elderly patients, early initiation of dialysis may be required to maintain adequate nutritional status. ${ }^{17}$ Although further studies are required, pneumonia could be an important risk factor for early initiation of dialysis in elderly DN patients with ESRD.

The extent of immune dysfunction in DN patients with ESRD is unclear, but it has been reported that the outcomes of hospitalization for infection are 3-4-fold worse in people with

Table 2 Univariate and multivariate analysis of risk factors for early dialysis

\begin{tabular}{llllll}
\hline Variable & \multicolumn{2}{l}{ Univariate analysis } & & \multicolumn{2}{c}{ Multivariate analysis } \\
\cline { 2 - 3 } & Odds ratio & P-value & & Odds ratio & P-value \\
\hline Male sex & 6.75 & 0.052 & & 8.45 & 0.080 \\
Elderly patient & 7.69 & 0.006 & & 4.59 & 0.030 \\
Heart failure & 1.94 & 0.253 & & 3.30 & 0.100 \\
Hyperlipidemia & 0.46 & 0.221 & & \\
Anemia & 1.80 & 0.618 & & 2.26 & 0.553 \\
Malignancy & 2.00 & 0.325 & & \\
\hline
\end{tabular}

Note: Elderly was defined as age $\geq 65$ years.

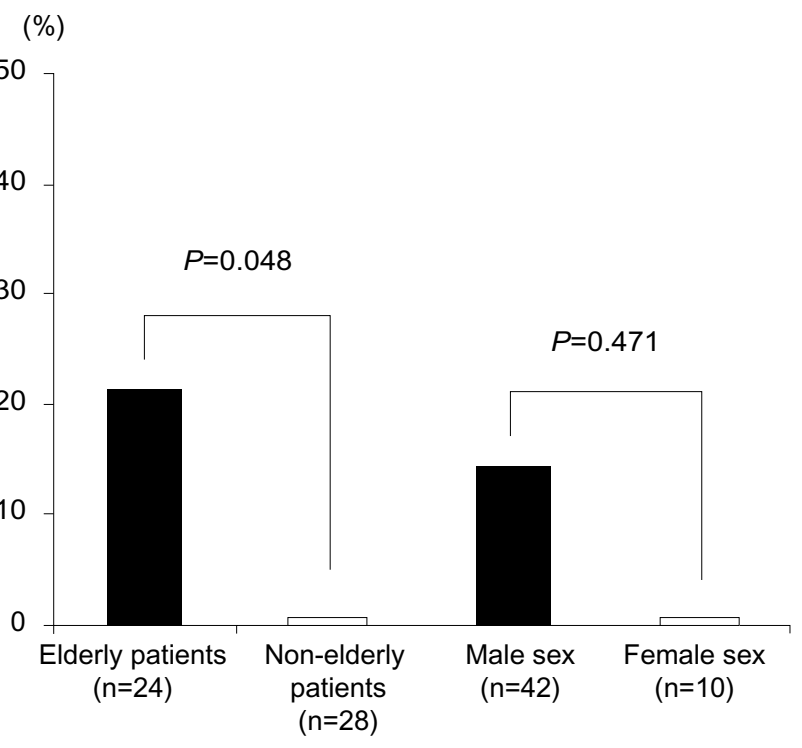

Figure I Incidence rates of pneumonia before starting dialysis.

Notes: (A) Results for elderly and nonelderly patients. (B) Results according to sex. $P$-values were determined by the Fisher's exact test. Elderly patients were defined as those aged $\geq 65$ years. The incidence of pneumonia before starting dialysis was significantly higher in elderly patients than in nonelderly patients, with no significant difference between male and female patients.

CKD than in those without CKD. ${ }^{18}$ Also, the mortality associated with pulmonary infection in ESRD patients is 14-16-fold higher than in non-ESRD patients. ${ }^{19}$ Therefore, the Advisory Committee on Immunization Practices recommends that ESRD patients receive booster pneumococcal vaccination when the antibody titer decreases below $200 \mu \mathrm{g} / \mathrm{L} .{ }^{2}$ To avoid early dialysis, booster pneumococcal vaccination could be useful in elderly patients with DN and ESRD.

Our study had some limitations. First, it was retrospective and the number of subjects was small, so our results lack statistical power and have a source of bias. Although the increase in risk was not significant, sex could potentially be a more important predictor than old age. Thus, larger prospective and/or multicenter studies will be needed to validate our results. Second, information about booster vaccination is not routinely included in patient medical records, so prospective studies focusing on the usefulness of booster pneumococcal vaccination are required.

\section{Conclusion}

The present findings suggest that elderly patients with DN and ESRD have a high risk of early initiation of dialysis, and that occurrence of pneumonia may be associated with early dialysis. Booster pneumococcal vaccination could be recommended for elderly DN patients with ESRD to avoid early dialysis. 


\section{Disclosure}

The authors report no conflicts of interest in this work.

\section{References}

1. Japanese Society for Dialysis Therapy. [Guidelines for maintenance hemodialysis: hemodialysis prescriptions]. J Jpn Soc Dial Ther. 2013;46: 587-632. Japanese.

2. Choudhury D, Luna-Salazar C. Preventive health care in chronic kidney disease and end-stage renal disease. Nat Clin Pract Nephrol. 2008;4: 194-206.

3. Bonomini V, Feletti C, Stefoni S et al. Early dialysis and renal transplantation. Nephron. 1986;44:267-271.

4. Bonomini V, Vangelista A, Stefoni S et al. Early dialysis in renal substitutive programs. Kidney Int Suppl. 1978;8:S112-S116.

5. Tattersall J, Greenwood R, Farrington K, et al. Urea kinetics and when to commence dialysis. Am J Nephrol. 1995;15:283-289.

6. Beddhu S, Samore MH, Roberts MS, et al. Impact of timing of initiation of dialysis on mortality. J Am Soc Nephrol. 2003;14:2305-2312.

7. Kazmi WH, Gilbertson DT, Obrador GT, et al. Effect of comorbidity on the increased mortality associated with early initiation of dialysis. Am J Kidney Dis. 2005;46:887-896.

8. Lassalle M, Labeeuw M, Frimat L, et al. Age and comorbidity may explain the paradoxical association of an early dialysis start with poor survival. Kidney Int. 2010;77:700-707.

9. Stel VS, Dekker FW, Ansell D, et al. Residual renal function at the start of dialysis and clinical outcomes. Nephrol Dial Transplant. 2009;24: 3175-3182.
10. Traynor JP, Simpson K, Geddes CC, et al. Early initiation of dialysis fails to prolong survival in patients with end-stage renal failure. $J A m$ Soc Nephrol. 2002;13:2125-2132.

11. Cooper BA, Branley P, Bulfone L, et al. A randomized, controlled trial of early versus late initiation of dialysis. N Engl J Med. 2010;363: 609-619.

12. Pan Y, Xu XD, Guo LL, Cai LL, et al. Association of early versus late initiation of dialysis with mortality: systematic review and metaanalysis. Nephron Clin Pract. 2012;120:121-131.

13. O'Toole SM, Fan SL, Yaqoob MM, et al. Managing diabetes in dialysis patients. Postgrad Med J. 2012;88:160-166.

14. Levey AS, de Jong PE, Coresh J, et al. The definition, classification, and prognosis of chronic kidney disease: a KDIGO Controversies Conference report. Kidney Int. 2011;80:17-28.

15. Matsuo S, Imai E, Horio M, et al. Revised equations for estimated GFR from serum creatinine in Japan. Am J Kidney Dis. 2009;53:982-992.

16. European Best Practice Guidelines Expert Group on Hemodialysis, European Renal Association. Section I. Measurement of renal function, when to refer and when to start dialysis. Nephrol Dial Transplant. 2002;7:S7-S15.

17. Hakim RM, Lazarus JM. Initiation of dialysis. J Am Soc Nephrol. 1995;6:1319-1328.

18. Naqvi SB, Collins AJ. Infectious complications in chronic kidney disease. Adv Chronic Kidney Dis. 2006;13:199-204.

19. Chen $\mathrm{CH}, \mathrm{Hsu} \mathrm{WH}, \mathrm{Chen} \mathrm{HJ}$, et al. Different bacteriology and prognosis of thoracic empyemas between patients with chronic and end-stage renal disease. Chest. 2007;132:532-539.
Therapeutics and Clinical Risk Management

\section{Publish your work in this journal}

Therapeutics and Clinical Risk Management is an international, peerreviewed journal of clinical therapeutics and risk management, focusing on concise rapid reporting of clinical studies in all therapeutic areas, outcomes, safety, and programs for the effective, safe, and sustained use of medicines. This journal is indexed on PubMed Central, CAS,

\section{Dovepress}

EMBase, Scopus and the Elsevier Bibliographic databases. The manuscript management system is completely online and includes a very quick and fair peer-review system, which is all easy to use. Visit http://www.dovepress.com/testimonials.php to read real quotes from published authors. 